\title{
Effect of poor road network and maintenance on safety and security in Delta State Nigeria: Mixed perceptions in industrialized oil-producing community
}

\author{
Akuirene $\mathrm{OA}^{1,2}$, Atie $\mathrm{MO}^{1}$, Ishiekwene $\mathrm{CM}^{1}$ and Nwose $\mathrm{EU}^{2,3}$ \\ ${ }^{1}$ Department of Industrial Safety \& Environmental Management Technology, Delta State School of Marine Technology, Nigeria \\ ${ }^{2}$ Department of Public and community Health, Novena University Ogume, Nigeria \\ ${ }^{3}$ School of Community Health, Charles Sturt University, Australia
}

\begin{abstract}
Background: Factors influencing road transport accidents include human and non-human. The extent that non-human factors increases accidents has yet to exhaustively evaluated, especially in Delta State Nigeria.

Objective: To access the perception about road networks. Also, to model the effects of poor road network (PRN) on vehicle repairs; and road maintenance on occupational health and safety (OHS) issues in Delta state, Nigeria.

Method: This study adopted a survey approach. Likert scaled questionnaire was used to survey the perception of different stakeholders. The responses were used to model the effects of environmental and mechanical factors of road traffic accidents. ANOVA and regression modelling techniques were performed.

Results: This study shows mixed perceptions from respondents. 64\% of responses agreed on state of the roads being poor while a lower (49\%) indicate insecurity on the roads. Modelling shows over 32\% increases in vehicle repairs and OHS concerns attributable to PRN and road maintenance respectively.

Conclusion: This report highlights gap in knowledge about road traffic, which calls for OHS education. This educational promotion need is adoptable particularly in low-mid income countries where PRN remains an OHS issue, but also relevant in developed countries as unhealthy driving behaviour is still a factor of drivers' perceptions.
\end{abstract}

\section{Introduction}

It is common knowledge that road traffic mortality is more prevalent in low- and mid-income countries compared to the developed nations $[1,2]$; and this is attributable to good roads as well as safety policy implementation that have yet to develop commensurably along with economic development [3]. Nigeria recorded her first traffic accident in Lagos in 1906 and purportedly remained low over a long time in the country due largely to low vehicular population. It argued that from the 1970s following remarkable improvements in the economic prosperity in the country arising from the oil boom, the magnitude of the accident problem increased [4]. However, the effect of bad roads has yet to be really evaluated in some of the oil-producing communities.

It is known that the restrictive nature of the travelling routes including lack of waterways and railway system, as well as the inability of an average Nigerian to afford the high cost of air travel makes road transportation preferable in Nigeria [4]. The discovery of oil in Nigeria opened new frontiers of economic engagement, especially at the Delta state including Udu local government area (Udu LGA). The distribution of refined products across the country has been a thorn in the side of many Nigerians. In 2011, the Federal Road Safety Corps (FRSC) reported that Nigeria has an average of approximately 5,000 tankers involved in wet cargo haulage, moving about 150 million litres of fuel, and 2,500 "trailers" in dry cargo plying Nigeria's roads daily [5]. It was also revealed that between 2007 and June 2010 (31/2 years period), a total of 4,017 tanker/trailer crashes including 4,076 deaths were recorded on Nigerian roads, which is average of 96 crashes/month and 3.2 road traffic accident (RTA) deaths/day [6].

Further, metric tons of agricultural crops in Nigeria were produced. Transporting these products in trucks via roads plagued with potholes and congestion has caused several fatal road accidents. The implication is burden of occupational health and safety (OHS) problems [3]. Indeed, Nigeria registers average of 39000 RTA deaths annually, which is about 107 deaths/day [7]. Surely this is a cause for concern. Thus, the main objective of this paper is to access the effect of poor road network and maintenance in tackling safety and security issues in Udu LGA of Delta State. The specific objectives are to:

1. Examine the state of the road networks in Udu LGA of Delta State

2. Determine the effect of poor road network (PNR) on vehicle maintenance

${ }^{*}$ Correspondence to: Akuirene O. Alero, Department of Public and Community Health, Novena University, Ogume, Nigeria, Tel: +234-8034932598; E-mail: akuireneomatseye@gmail.com

Key words: Occupational health and safety (OHS), perceptions in community, poor road networks, road maintenance

Received: November 10, 2020; Accepted: December 08, 2020; Published: December 15, 2020 


\section{Assess the effect of poor road maintenance on OHS}

Hypotheses: PNR has no significant effect on vehicle maintenance. Second, road maintenance has no significant effect on OHS.

\section{Materials and methods}

\section{Research design}

The design adopted the descriptive survey design. Likert scale questionnaire was used for data collection.

\section{Approval}

A letter of introduction was collected from the department of Industrial Safety \& Environmental Management Technology, Delta State School of Marine Technology, Burutu, Delta State in order to seek approval from the indigenes of the communities where the research would be carried out. To clear any misconceptions about the intentions of the study, an explicit overview of what the research entails and how the results will be utilized, was given to the respondents. Privacy and confidentiality of the respondents in order to gain confidence from them were adhered.

\section{Study place and population}

This study would be undertaken in Udu Local Government Area of Delta State. Udu is one of the major Local Government Area that makes up the twenty-five (25) Local Government Area of Delta State. Udu Local Government Area comprise of twenty-six (26) communities and these communities have their various kingship institutions and kingdom that lord over them. Most of these traditional rulers are often referred to as Ovie meaning King. The villages that makes up of the present Udu Local Government Area are historically grouped into three sub-clans, namely: Evwrirhe Sub-Clans, Oniere Sub-Clan and Uheredjo Sub-Clans. The population of this study consists of road users in Udu Local Government Area. These road users consist of over 1000 frequent/regular users.

\section{Selection Criteria}

There are 26 communities in Udu Local Government Area, out of which, five communities were chosen randomly for this research, which are Ovwian, Owhase, Orhuwhorun, Egini and Ujevwu community and 20 questionnaires were administered to road users which comprises of transporters, traders and passengers randomly in each community totaling 100 questionnaires in all. This was carried out at their houses and garages in the region.

\section{Sampling Procedure}

A stratified and systematic sampling technique was used to administer 100 questionnaires to road users around the community. The community and environs were stratified into five, Ovwian community, Owhase community, Orhuwhorun community, Egini community and Ujevwu community to insure that every section of its metropolis participated.

\section{Method of Data Analysis}

The data collected was analyzed using descriptive statistic of frequency counts and percentages and was obtained from two classes of sources namely the primary sources and the secondary sources. The primary sources include data generated from the administration of questionnaire and personal observation and interviews. The secondary sources, on the other hand, include textbooks, journals, magazines and newspapers. Others include conference papers, project works, data from relevant government agencies and internet materials. Inferential statistics, such as multiple regressions would be used. This would be calculated through the use of Statistical Package for Social Scientist (SPSS version 25). This analysis seeks to test the hypothesis of the study and explains the relationships and as well evaluates its strengths between the variables. The output would be presented in tabular forms.

Model effect of PRN as predicting factor on vehicle damage as dependent variable and also road maintenance as predicting factor on OHS (as dependent variable) was evaluated by the correlation coefficient (R). The regression analysis on effect of Road maintenance on safety and security was also performed. In this study, OHS comprised the safety and security of all road users. The definition was premised on the fact that everybody on the road has gone there for some forms of occupational activity of daily living, which in turn constitute a determinant of health.

\section{Results}

\section{Demographic analysis of the road users}

Analysis of the respondents' demography show males constituted $65 \%$. Majority (72\%) comprised family people who either are currently or were once married, and $79 \%$ own vehicles (Table 1). Those in the 50 59 years range made up nearly half of the volunteer participants, and $82 \%$ of them has post-secondary level of education.

The study aimed at propounding a model to predict OHS issues caused by PRN and its maintenance in Delta State Nigeria. From the data of stakeholders' belief collected, there are only few smooth motor able roads and also heavy traffic congestions on the road network as experienced by majority of the road users. The road networks are in deplorable state and as such only $42 \%$ of locations are accessible while about $50 \%$ are not accessible. Table 2 shows the descriptive statistics of responses to the questionnaire items per variables of the study. These central descriptive values were based on Likert scale strongly disagreed (1), disagree (2), unsure (3), agree (4) and strongly agreed (5). Thus, a mean value of $>3$ is considered affirmative while $<2$ is non-affirmative of the question.

From the responses of the respondents, $43 \%$ of the respondents strongly agreed that at current state, there is no smooth motor able

Table 1. Demography of respondents $(\mathrm{N}=100)$.

\begin{tabular}{|c|c|c|c|}
\hline \multicolumn{2}{|l|}{ Variables } & \multirow{2}{*}{$\begin{array}{l}\text { Frequency } \\
65\end{array}$} & \multirow{2}{*}{\begin{tabular}{|l|} 
Cumulative Percent \\
65
\end{tabular}} \\
\hline$S_{0}$ & Male & & \\
\hline Sex & Female & 35 & 100 \\
\hline \multirow{5}{*}{ Age } & $18-29$ & 10 & 10 \\
\hline & $30-39$ & 15 & 25 \\
\hline & $40-49$ & 14 & 39 \\
\hline & $50-59$ & 47 & 86 \\
\hline & 60 and Above & 14 & 100 \\
\hline \multirow{4}{*}{ Marital Status } & Married & 39 & 39 \\
\hline & Single & 28 & 67 \\
\hline & Divorced & 14 & 81 \\
\hline & Widow/Widower & 19 & 100 \\
\hline \multirow{2}{*}{ Own a Vehicle } & Yes & 79 & 79 \\
\hline & No & 21 & 100 \\
\hline \multirow{4}{*}{ Educational status } & SSCE and Below & 18 & 18 \\
\hline & $\begin{array}{l}\text { Diploma or } \\
\text { Bachelors }\end{array}$ & 51 & 69 \\
\hline & Masters & 13 & 82 \\
\hline & PHD & 18 & 100 \\
\hline
\end{tabular}



community

Table 2. Data on effects of road networks.

\begin{tabular}{|c|c|c|c|c|}
\hline Theme & Questions & Mean & SD & Var \\
\hline \multirow{5}{*}{ State of road networks } & There are no motor able roads & 3.60 & 1.63 & 2.65 \\
\hline & There is heavy traffic congestion on the road network & 3.37 & 1.50 & 2.24 \\
\hline & Certain locations are not accessible & 3.29 & 2.63 & 6.90 \\
\hline & Road networks are deplorable & 3.01 & 1.38 & 1.91 \\
\hline & Due to raining season, roads under construction are abandoned, making road networks more complicated & 2.62 & 1.38 & 1.92 \\
\hline \multirow{5}{*}{ Poor road networks } & PRN has led to more consecration on road & 2.69 & 1.34 & 1.79 \\
\hline & There are complications about duality of the road lanes & 2.81 & 1.40 & 1.95 \\
\hline & There are roundabouts in place where there ought to be flyovers & 2.74 & 1.32 & 1.73 \\
\hline & There are gridlocks and bottle necks in the entrance, middle of the town & 2.75 & 1.38 & 1.91 \\
\hline & PRN has altered the timeframe of arriving at a particular destination & 3.00 & 1.40 & 1.96 \\
\hline \multirow{4}{*}{ Vehicle maintenance } & I visit my mechanic twice a month due to bad road & 2.80 & 1.36 & 1.84 \\
\hline & Bad road has led to damage of vital part of my vehicle & 3.30 & 3.19 & 10.17 \\
\hline & My car sensors and shock absorbers are all damaged & 2.83 & 1.35 & 1.82 \\
\hline & It has cost quite a significant amount to maintain my vehicle due to bad roads & 2.93 & 1.40 & 1.97 \\
\hline \multirow{4}{*}{ Road maintenance } & Road are not smooth, there are always rough & 2.81 & 1.40 & 1.95 \\
\hline & There has not been any proper maintenance and reconstruction of damage road & 2.74 & 1.32 & 1.73 \\
\hline & Road indicators \& danger sign are all damaged and not repaired & 2.75 & 1.38 & 1.91 \\
\hline & No special treatment of heavy-duty trucks and saloon cars & 3.00 & 1.40 & 1.96 \\
\hline \multirow{4}{*}{ Safety \& security (OHS) } & There are no clean and clear road markings, Road signs and lights in junctions & 2.20 & 1.16 & 1.83 \\
\hline & There is no enlightenment pertaining to speed limits & 3.10 & 3.29 & 9.15 \\
\hline & There is no VISCAR (Visual average speed computer and Recorder) & 2.23 & 1.15 & 1.83 \\
\hline & The traffic light does not work well and it is not present in certain junctions & 2.33 & 1.10 & 1.94 \\
\hline
\end{tabular}

road $(P<0.001)$. It can be said that there are no smooth motor able roads in the study area. Then for traffic congestions, strongly agreed and agreed happens to have the highest chi-square residuals. This implies that there are heavy traffic congestions on the road network $(p<$ 0.003 ). For the accessibility of certain locations, the responses are mix, as $49 \%$ of the respondents agreed that certain locations are accessible while $42 \%$ disagreed and remaining other being unsure (Figure 1). The same but varying proportions of mixed responses were observed in other investigated themes (Table 2). Critical review of the results on Table 2 show that on average, there level of perception regarding assessed themes are

- poor state of roads: $64 \%$

- poor road networks (PNR): $56 \%$

- effect of PNR on vehicle maintenance: $59 \%$

- level of road maintenance: $57 \%$

- effect of road maintenance on OHS: $49 \%$

\section{Effect of road network on vehicle maintenance}

From the analysis, a little homoscedasticity of responses as regard the model is observed (Figure 2). The correlation coefficient between $\mathrm{PNR}$ and vehicle maintenance was positive $(\mathrm{R}=0.576)$; and coefficient of determination that measures covariance between PNR and vehicle maintenance is ' $\mathrm{R}^{2}=0.332$ ' $(p<0.001)$. Based on this, the null hypothesis is rejected, and alternate hypothesis accepted - i.e., PNR has significant positive effect on vehicle maintenance. The result of the regression analysis revealed that poor road network has a significant impact on vehicle maintenance. This implies the rate of damage it does to vehicle has eventually increased the rate at which vehicle owners take their vehicles for maintenance. In light of this, an increase in poor road

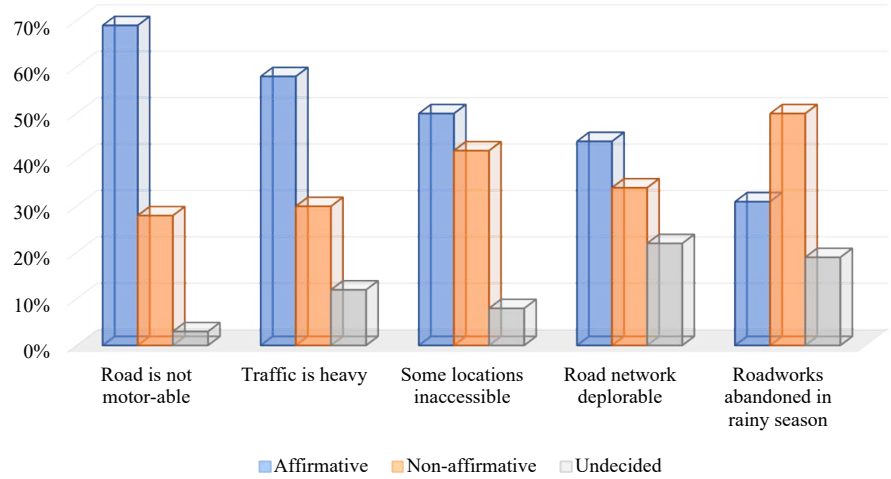

Figure 1. Perception of participants regarding the roads being motor able.

networks will eventually increase the frequency of one taking its vehicle for maintenance.

\section{Effect of road maintenance on OHS}

Table 3 shows the results of the regression analysis on effect of road maintenance on OHS that the Beta value is 0.563 representing potential $56 \%$ increase in OHS as result of improvement in road maintenance, or vice versa $(p<0.001)$. Although, homoscedasticity of responses is also affirmed (Figure 3). Alternative view of the result is $32 \%$ increase in OHS concerns is attributable to road maintenance $(\mathrm{R}=0.56)$. Therefore, based on this, the null hypothesis is also rejected and alternate hypothesis accepted - road maintenance has no significant effect on safety and security. The result from the regression analysis posits a positive relationship existing between both variables and as such an increase in the road maintenance will enhance OHS in Delta State. For a decrease in death rate, rate of accident on the road among other safety issues, there have to be a constant improvement and continuous maintenance of roads. 
Akuirene OA (2020) Effect of poor road network and maintenance on safety and security in Delta State Nigeria: Mixed perceptions in industrialized oil-producing community

Table 3. Regression results.

\begin{tabular}{|c|c|c|c|c|c|c|}
\hline \multirow{2}{*}{\multicolumn{2}{|c|}{ Model }} & \multicolumn{2}{|c|}{ Unstandardized Coefficients } & \multirow{2}{*}{$\begin{array}{c}\text { Standardized } \\
\text { Coefficients }\end{array}$} & \multirow[t]{2}{*}{ Test statisics } & \multirow[t]{2}{*}{ Significance } \\
\hline & & B & Standard Error & & & \\
\hline \multirow{2}{*}{1} & (Constant) & 0.886 & 0.323 & & 2.742 & 0.007 \\
\hline & Road Maintenance & 0.736 & 0.109 & 0.563 & 6.746 & 0 \\
\hline
\end{tabular}

\section{Scatterplot}

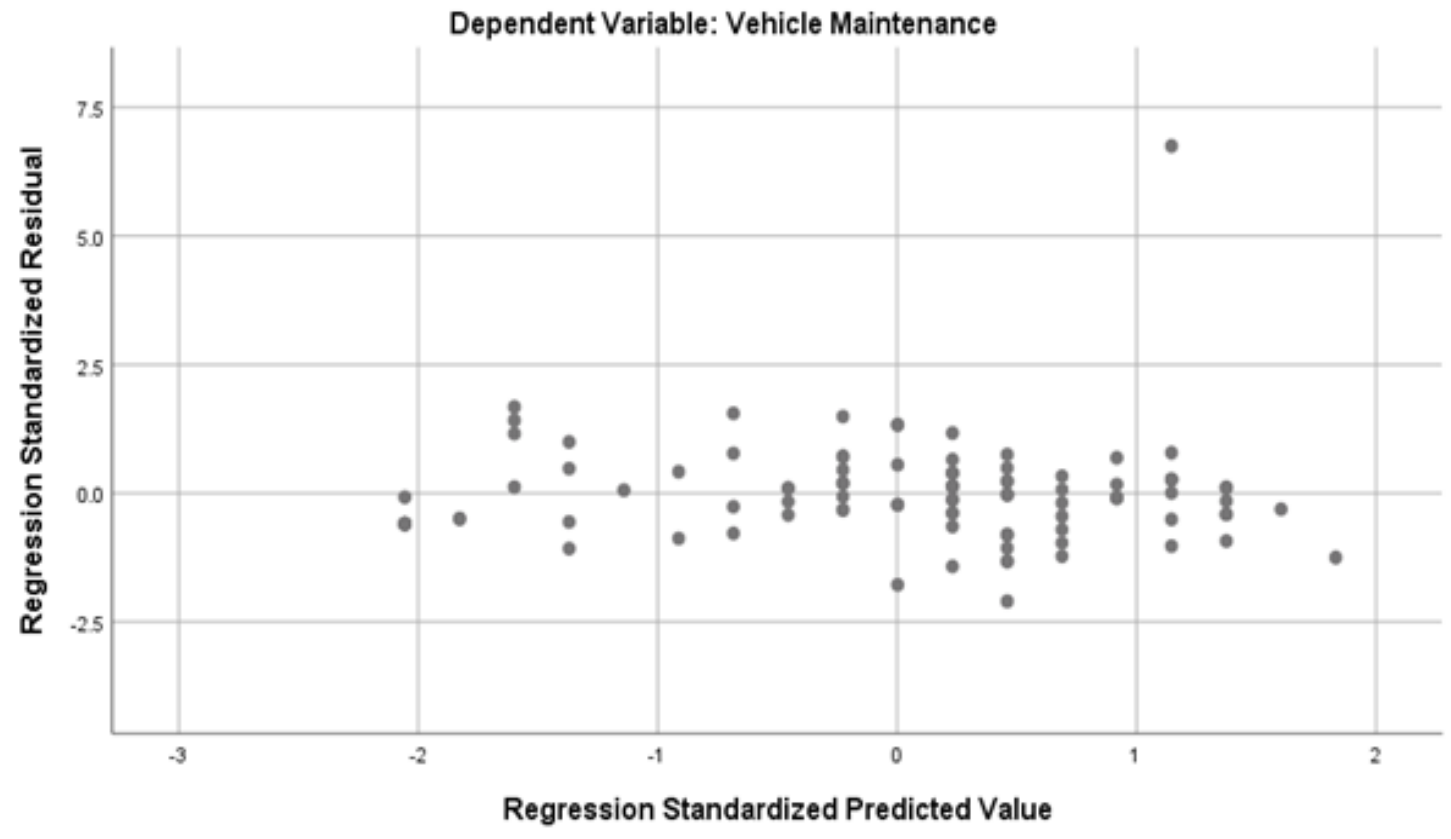

Figure 2. Homoscedasticity of responses as regard the model.

\section{Scatterplot}

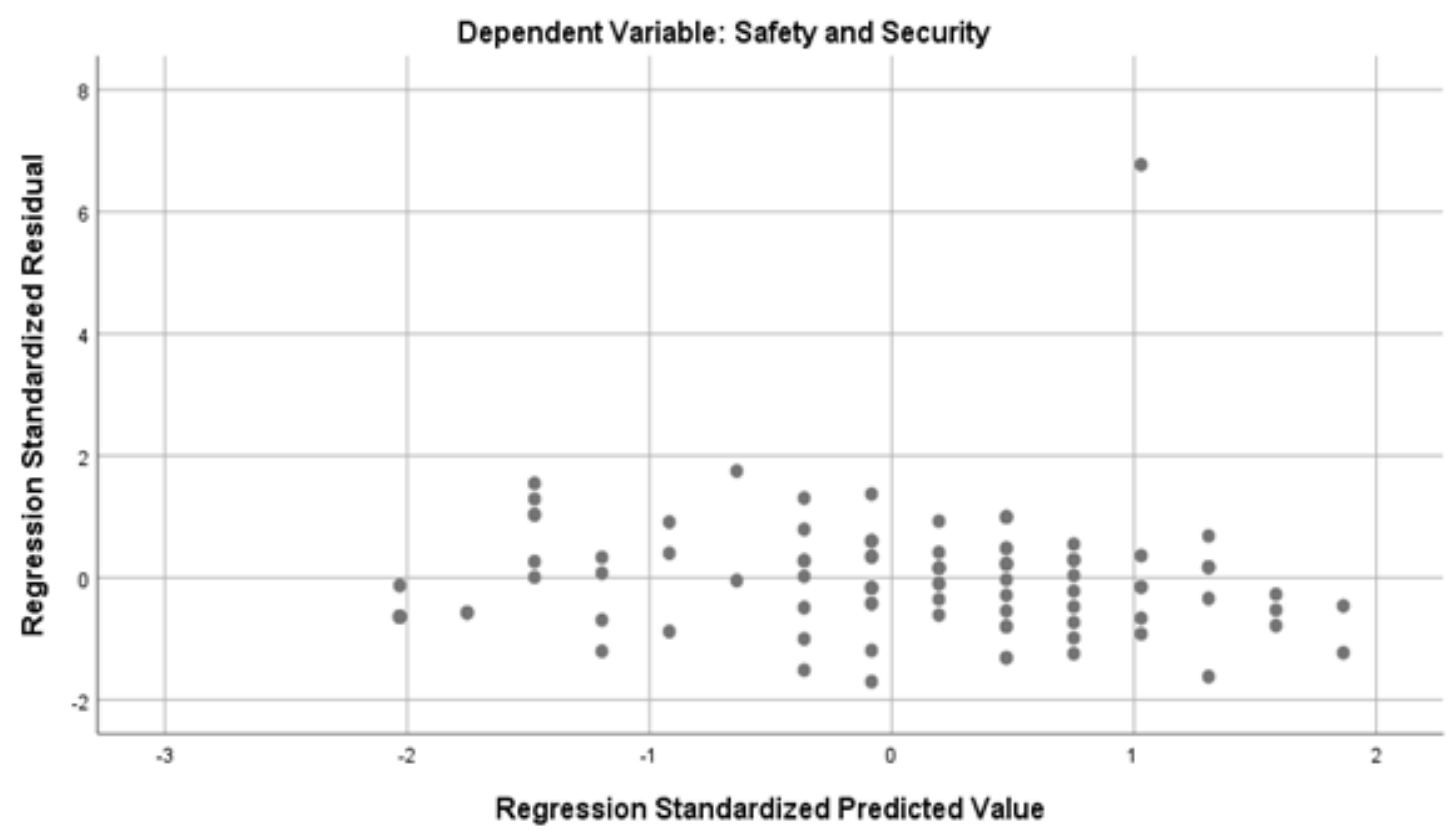

Figure 3. Homoscedasticity of responses as regard the model. 


\section{Discussion}

On the first research objective: the research findings indicate that the present state of the road network in the region is very bad and has been a huge cause for alarm. There are only few smooth motor able roads in the region and heavy traffic congestions on the road network as experienced by majority of the road users. On the second objective: the findings from the research question shows that road networks in the region are in deplorable state with complications about the duality of road lanes, existence of roundabouts in place where there ought to be flyovers. Although many locations are accessible, some are in very poor state. Increase in rate of vehicle maintenance is attributable to major changes regarding road network. Bad roads increase the rate of damage on vehicle which has eventually increased the rate at which vehicle owners takes their motors for repairs. The relationship between PNR and vehicle maintenance is a significant one. Finally, on the third objective: the findings of the research question revealed that majority of the roads in the region are not smooth but rough, and also there has not being proper maintenance nor repairs of damaged roads, road indicators, danger signs, traffic lights amongst others. Apparently, these will eventually lead to increase in accident rate and amounts to loss of lives and infliction of injuries on victims, which constitute the hallmark of OHS.

Table 3 indicates that increase in OHS is attributable to road maintenance. From the scatter plots, there exists just one outlier on each of the two models. The cloudiness of the dots in the plot indicates the presence of homoscedasticity, implying that the responses of the respondents all have same variance mean. There exist no wide variances in the responses.

\section{Implication for tackling OHS issues on the roads}

There is no gain saying what is already known that road traffic accidents are caused by convoluted factors of human and non-human (environmental and mechanical) failures $[8,9]$; or that an increase in road maintenance will enhance OHS [10]. However, for a rate of accident on the road and the attendant OHS issues, there have to be a constant improvement on the factors. This particularly includes awareness OHS education as well as project management. What this report contributes is the low level of awareness among the people.

For instance, the result of this study indicates level of perception regarding effect of road maintenance on OHS is $49 \%$. In other words, more than half of the population are yet to appreciate the various ways that road maintenance impacts on their OHS. The implication is that even if the government is trying to do the right thing, the lack of knowledge by the people may unknowingly frustrate the effort. This is because the necessary factor of whether stakeholders know what to do in a project is missing. This factor of ignorance was implied in the perspective of compliance to traffic laws reported from the northern part of the country [4]. Several studies have made recommendations on 'what to do' in addressing the issue of road traffic accidents on Nigerian roads [8-10]. What this report contributes to the discourse is that the low level of sensitivity to safety and security facilities such as road signs, traffic lights, and speed limits are genuine matters of lack of knowledge.

At the international level, it is common knowledge that drivers violate traffic rules [11-13]. What this report is model-based emphasis that perspectives of the road users determine the associated OHS behavior [11-13]; and can be used as predicting factor [14]. Given that knowledge is power, it implies that there is need to empower the people. Additionally, it is proposed for OHS education purpose and possibly further corroborative study that road maintenance may reduce road accidents by one-third. This proposition resonates with recommendation from international communities such as Iran to promote healthy driving behaviors among drivers [11].

\section{Conclusion}

This study employed survey research design to examine the effect of PNR and maintenance in tackling OHS issues on the roads in Delta State. PNR, road maintenance, vehicle maintenance, and OHS were the variables used as measurement parameters. The findings of the study reveal for the local level, that the present's condition of road network is bad, but not everybody think so. Also, PNR increases vehicle maintenance and finally, the more effort put towards road maintenance can improve OHS incidents by over $32 \%$. At the international level, this report contributes to advance the need of addressing drivers' risky attitudes as lack of knowledge. It is recommended to include awareness campaign that will improve the peoples' sensitivities to OHS factors.

\section{Authors' Contributions}

Akuirene led the research team and at all stages including conceptualization of PRN survey, data collection and manuscript drafting. Atie and Ishiekwene were involved in data collection and first draft of the manuscript. Nwose was involved in discussion of the results as well as editing the first draft to produce second draft with articulation of OHS and health promotion concepts. After other coauthors have reviewed the second draft, Nwose did the revision to produce the final version.

\section{Conflicts of interest}

There are no conflicts of interest to be declared.

\section{Acknowledgements}

Support of the head of department, Industrial Safety \& Environmental Management Technology, Delta State School of Marine Technology is highly appreciated. Students from the department have also help in distributing and retrieving the survey questionnaire and are hereby acknowledged.

\section{References}

1. Onyemaechi NOC, Ofoma UR (2016) The Public Health Threat of Road Traffic Accidents in Nigeria: A Call to Action. Ann Med Health Sci Res 6: 199-204. [Crossref]

2. Lagarde E (2007) Road traffic injury is an escalating burden in Africa and deserves proportionate research efforts. PLoS Med 4: e170-e170. [Crossref]

3. Adeloye D, Thompson JY, Akanbi MA, Azuh D, Samuel V, et al. (2016) The burden of road traffic crashes, injuries and deaths in Africa: a systematic review and metaanalysis. Bull World Health Organ 94: 510-521A. [Crossref]

4. Iyanda $\mathrm{AE}$ (2019) Geographic analysis of road accident severity index in Nigeria. Int $J$ Inj Contr Saf Promot 26: 72-81. [Crossref]

5. Federal Road Safety Corps (2011) 2011 annual report. Available at: https://frsc.gov.ng/ frscreport2011.pdf. [Accessed 15 March 2020].

6. Federal Road Safety Corps (2018) Road safety report: Nigeria. International Transport Forum. Available at: https://www.itf-oecd.org/sites/default/files/nigeria-road-safety. pdf. [Accessed 15 March 2020].

7. World Health Organization (2019) Fifth United Nations Global Road Safety Week - Nigerian Government re-commits to road safety. Available at: https://www.afro. who.int/news/fifth-united-nations-global-road-safety-week-nigerian-government-recommits-road-safety. [Accessed 16 September 2020]

8. Mohammed AA, Ambak K, Mosa AM, Syamsunur D (2019) A review of traffic accidents and related practices worldwide. The Open Transportation J 13: 65-83. 
Akuirene OA (2020) Effect of poor road network and maintenance on safety and security in Delta State Nigeria: Mixed perceptions in industrialized oil-producing community

9. Afolabi JO, Gbadamosi Kolawole T (2017) Road traffic crashes in Nigeria: Causes and consequences. Int J Shipping Transport Logistics 17: 40-49.

10. Atubi AO, Onokala PC (2009) Contemporary Analysis of Variability in Road Traffic Accidents in Lagos State, Nigeria. African Geographical Rev 28: 11-41.

11. Mardani Z, Pirzadeh A (2018) Driving behaviors and the influential factors in the taxi drivers in Isfahan City, Iran (2017). J Human Environ Health Promotion 4 186-190.
12. Jamalizadeh Z, Safari Variani A, Ahmadi S, Asivandzadeh E (2018) Association of road traffic noise exposure and driving behaviors. J Human Environ Health Promotion 4: 111-115.

13. Holman AC, Popusoi SA. Ethical predispositions to violate or obey traffic rules and the mediating role of driving sStyles. J psychol 152: 257-275. [Crossref]

14. Lucidi F, Girelli L, Chirico A, Alivernini F, Cozzolino M, et al. (2019) Personality traits and attitudes toward traffic safety predict risky behavior across young, adult, and older drivers. Front psychol 10: 536. [Crossref]

Copyright: (C2020 Akuirene OA. This is an open-access article distributed under the terms of the Creative Commons Attribution License, which permits unrestricted use, distribution, and reproduction in any medium, provided the original author and source are credited. 